\title{
Repeated praziquantel treatments remodel the genetic and spatial landscape of schistosomiasis risk and transmission
}

\author{
Lúcio M. Barbosa ${ }^{\mathrm{a}, \mathrm{b}}$, Eliana A. Reis ${ }^{\text {a }}$, Cláudio R.A. dos Santos ${ }^{\mathrm{a}}$, Jackson M. Costa ${ }^{\mathrm{a}}$, Theomira M. Carmo ${ }^{\mathrm{a}}$, \\ Peace T. Aminu ${ }^{c}$, Thassila N. Pitanga ${ }^{a}$, Rafael Ponce-Terashima ${ }^{d}$, Walter A. Blank ${ }^{c}$, Luciano K. Silva ${ }^{\mathrm{a}}$, \\ Mitermayer G. Reis ${ }^{\mathrm{a}, \mathrm{b}}$, Ronald E. Blanton ${ }^{\mathrm{c}, *}$ \\ ${ }^{a}$ Gonçalo Moniz Research Centre, Oswaldo Cruz Foundation, Rua Waldemar Falcão, 121 Brotas, Salvador, Bahia 40296-710, Brazil \\ ${ }^{\mathrm{b}}$ Bahiana School of Medicine and Public Health, Av. Silveira Martins, $n^{\circ}$ 3386, Salvador, Bahia 41150-100, Brazil \\ ${ }^{c}$ Center for Global Health and Diseases, Case Western Reserve University, Biomedical Research Building, 2109 Adelbert Rd., Cleveland, OH 44106, USA \\ ${ }^{\mathrm{d}}$ Mercer University School of Medicine, 1327 Stadium Drive, Macon, GA 31207-1302, USA
}

\section{A R T I C L E I N F O}

\section{Article history:}

Received 7 November 2015

Received in revised form 25 January 2016

Accepted 28 January 2016

Available online 4 March 2016

\section{Keywords:}

Effective population size

Genetic differentiation

Extinction

Praziquantel

Reinfection

Spatial analysis

Brazil

\begin{abstract}
A B S T R A C T
Repeated treatments with praziquantel reduce schistosomiasis prevalence and morbidity, but transmission persists and populations often recover within a few years. To identify factors associated with persistence, we surveyed and treated all identified Schistosoma mansoni infections in two rural Brazilian communities (Jenipapo and Volta do Rio) in 2009, 2012 and 2013. Eggs were collected from all infected individuals and genotyped with 11 microsatellite markers to evaluate parasite differentiation and diversity. After successive rounds of community-wide treatment, prevalence decreased from $45 \%$ to $24 \%$ then $16 \%$. Intensity of infection decreased by $57 \%$ over this period, and the number of eggs transmitted to the environment decreased by $92 \%$. During all time periods the majority of eggs were excreted by those $>15$ years of age. The incidence was $23 \%$ in 2012 and $15 \%$ in 2013, consistent with a decrease in transmission. There was little immigration or gene flow over a distance of $6 \mathrm{~km}$. On reinfection, infrapopulations were moderately differentiated indicating that pretreatment multilocus genotypes were not fully reacquired. The effective population size responded to census population decline more rapidly than differentiation. Reinfection was concentrated in the downstream portion of Jenipapo, consistent with the observed increased human fecal contamination. At this scale and in this area S. mansoni infections exist on a fragmented landscape with a highly focal pattern of transmission that may facilitate future elimination.
\end{abstract}

(ㄷ) 2016 Australian Society for Parasitology Inc. Published by Elsevier Ltd. All rights reserved.

\section{Introduction}

Despite advances in the treatment and prevention of schistosomiasis, it remains a major public health problem in Brazil and much of the world (World Health Organization (WHO), Schistosomiasis: Fact sheet $\mathrm{N}^{\circ} 115,2014$, http://www.who.int/mediacentre/factsheets/fs115/en/). In Brazil, estimates of those infected with Schistosoma mansoni range from 2.5 to 12 million, and more than 30 million are at risk of infection (Katz and Peixoto, 2000). Control strategies focusing on treatment with antiparasitic drugs were initiated in the 1970s. This reduced overall prevalence in endemic areas from $25 \%$ to approximately $5 \%$ by 2011 , with consequent steep reductions in morbidity (Carmo and Barreto, 1994; Coura and Amaral, 2004; Amaral et al., 2006) and mortality

\footnotetext{
* Corresponding author. Tel.: +1 216368 4814; fax: +1 2163684825.

E-mail address: reb6@case.edu (R.E. Blanton).
}

(Ferreira and Tabosa e Silva, 2007), but without eliminating transmission. There is no sterile immunity to schistosomes, thus reinfection is common.

As emphasis shifts from control to elimination, it is important to better understand the parasite's local population dynamics under pressure from antiparasitic treatments. Population genetics offers tools that can uncover many of the forces that modify parasite populations and may be useful for understanding parasite persistence despite repeated treatments. Population genetics has particularly been applied to problems of conservation in order to plan for the maintenance and health of organisms and ecosystems (Spielman et al., 2004; Frankham, 2005). By contrast, in the management of pathogens, extinction is the desired outcome, and identifying predictive markers and tracking progress toward this end are important objectives.

To date, few studies have tracked schistosome populations longitudinally following treatment and these report differing results. 
Significant parasite allele frequency differences were found in children in Tanzania before and after school-based treatment, suggesting that a single round of treatment produced a significant genetic bottleneck (Norton et al., 2010). In Senegal, a cohort of children was treated up to five times over 2 years (Huyse et al., 2013). After an initial decrease in prevalence, infection recurred with generally higher intensity in subsequent surveys. No change was found in parasite allelic richness, heterozygosity, inbreeding coefficient or fixation index. A 4 year mass drug administration program in Kenya showed no change in parasite genetic diversity in children with no decline in infection intensity (Lelo et al., 2014). These studies may not be contradictory since the dynamics of transmission vary between sites. Each study followed up school-based treatment and all examined small samples of parasites from small samples of infected individuals. While these are useful and provocative initial studies, they do not address the effect of community-wide treatment, the problem of reinfection versus persistence and in one case (Norton et al., 2010) does not reflect the result of individual reinfection. More and diverse sites need to be studied given the heterogeneity in worldwide human and parasite populations as well as the variation in environmental contexts. We propose that using "reverse" conservation genetics can contribute to planning and understanding the requirements for parasite elimination.

In 2009 we began studies on a rural focus of S. mansoni transmission in two small communities in Brazil. We registered host epidemiologic characteristics and parasite allele frequencies, and treated all of those infected (Barbosa et al., 2013). This population was then followed for two additional rounds of treatment over a 4 year period, and the longitudinal effects of treatment on parasite population dynamics and structure were analyzed.

\section{Materials and methods}

\subsection{Study sites and written consent}

The study was conducted in two rural villages, Jenipapo and Volta do Rio, along the Jiquiriçá River in the northeastern Brazilian state of Bahia. The communities each have 300-400 residents, are $6 \mathrm{~km}$ apart by road, share schools and health services, and they are each $10-15 \mathrm{~km}$ from larger towns (Fig. 1). This relative isolation, together with the prevalence of schistosomiasis in the area, were the main reasons for choosing these sites. The two communities have been described previously (Blanton et al., 2011; Barbosa et al., 2013).

Written consent was obtained from all participants or their guardians, and the study adhered to procedures approved by the Committee on Ethics in Research of the Oswaldo Cruz Foundation of Salvador, Bahia, Brazil, the Brazilian National Committee on Ethics in Research and the Institutional Review Board for Human Investigation of University Hospitals Case Medical Centre, Cleveland, Ohio, USA.

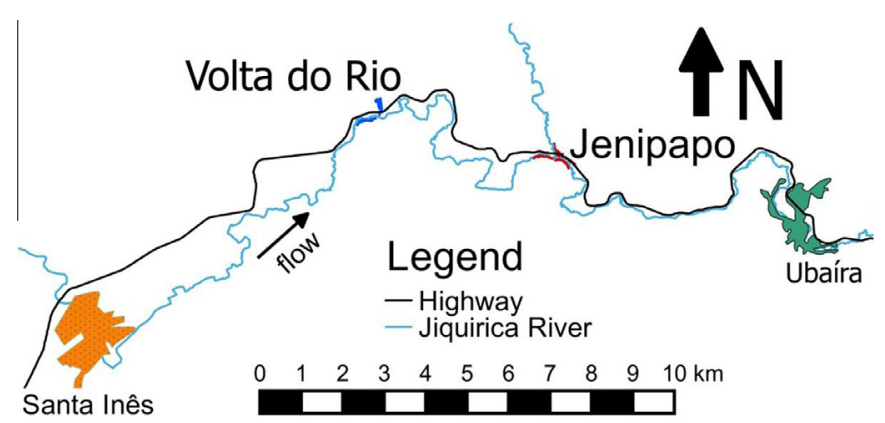

Fig. 1. Map of Ubaíra and Santa Inês areas in Brazil. Jenipapo and Volta do Rio are discrete communities $6 \mathrm{~km}$ apart, and each is $9 \mathrm{~km}$ distant from urbanised centres.

\subsection{Study design}

Epidemiologic and parasitologic surveys were conducted in both communities for all inhabitants $\geqslant 1$ year old who agreed to participate in 2009 and 2012 (Blanton et al., 2011; Barbosa et al., 2013). Only Jenipapo was studied in 2013 (Fig. 2). Information collected during each year of the study was double entered into the program Epi Info version 7 (Centers for Disease Control, Atlanta, GA, USA). For the parasitological survey, three stool samples were collected on different days from each resident and examined by the Kato-Katz technique for S. mansoni infection status and intensity recorded as eggs per gram (epg) of feces. Residents were directed to provide a whole stool for each examination. Infected individuals were treated with a single oral dose of praziquantel $(50 \mathrm{mg} / \mathrm{kg})$ according to Brazilian Ministry of Health guidelines (Ministério da Saúde, 2010). The first use of praziquantel in these communities was in 2009, and all subsequent treatments were directly observed. Those found to have soil-transmitted helminths received treatment with mebendazole. Four weeks after treatment, three stools collected on different days were again examined from S. mansoni-positive individuals, and those still positive were re-treated with mebendazole.

\subsection{Microsatellite genotyping}

All procedures and primers were previously described (Blank et al., 2009; Barbosa et al., 2013). Briefly, S. mansoni eggs were concentrated from the whole stool by selective sieving and sedimentation, and extracted DNA was PCR-amplified with a panel of primers for 11 microsatellites (Supplementary Table S1). The amplification products were combined into groups of three or four markers and processed on an Applied Biosystems 3730xl DNA Analyzer. PeakScanner software version 1.0 (Applied Biosystems, Carlsbad, CA, USA) was used to determine peak heights from which relative allele frequencies were calculated. Successful PCRs were defined as those in which there was at least one peak $>500$ pixels and measured peaks fell within the size range expected for a given marker. Peaks $<100$ pixels were excluded from analysis. If both duplicate samples amplified, their mean allele frequency was used. Subsequent population analyses were limited to those samples for which at least eight of 11 markers were successfully genotyped.

\subsection{Data analysis}

\subsubsection{Reinfection rates and statistical analyses}

Reinfection rates were calculated for individuals who were successfully treated in the previous year. Categorical data were

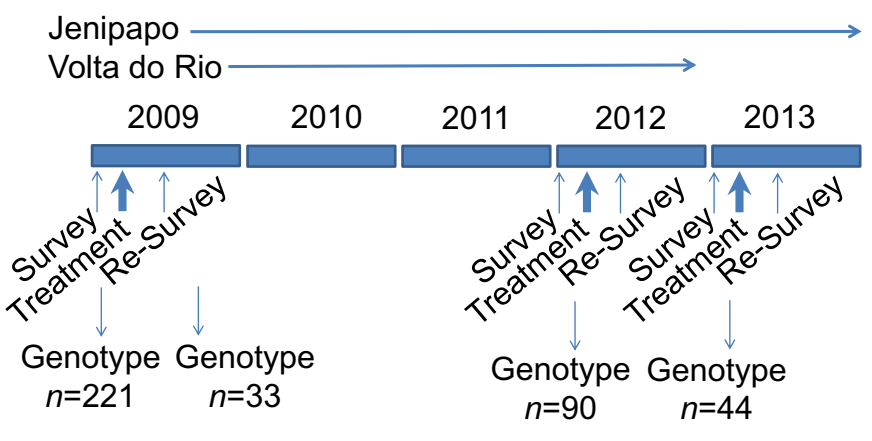

Fig. 2. Study design. Demographic and parasitologic surveys were conducted in 2009, 2012 and 2013. Those with stools positive for Schistosoma mansoni eggs were treated with praziquantel and re-examined after 4-6 weeks. Those with persistent infections were retreated. In 2012 and 2013 there were two and zero persistent infections, respectively. 
compared using Pearson's chi-square test, and continuous data was evaluated by Student's $t$-test or ANOVA after transformation for normality as needed. Tukey's test was performed post hoc for ANOVA analyses. A $P$ value of $<0.05$ was used as the criterion for statistical significance.

\subsubsection{Allele frequencies}

Total egg counts were calculated by multiplying the egg concentration by stool weight. Allele counts were calculated by multiplying total egg counts by the allele frequencies at a given microsatellite locus. Parasite populations and their allele frequencies were grouped into infrapopulations (the collection of schistosomes infecting an individual human host) and component populations (the aggregate of schistosomes infecting all hosts within a defined geographic area and/or period of analysis).

\subsubsection{Differentiation}

To assess genetic differentiation between populations we applied Jost's D index calculated using the program SPADE (Chao and Shen, 2010, http://chao.stat.nthu.edu.tw). The means of pairwise Jost's D comparisons between infrapopulations (Di) were averaged. Differentiation between component populations (Dc) used the total number of alleles in each component population to calculate D for each marker, and then those values were averaged. Due to the large number of eggs used to calculate $D$ and effective allele number, the $P$ value and the confidence intervals $(\mathrm{CI})$ rarely overlap. Cohen's D is a measure of effect size that is especially useful for large data sets where the null hypothesis is always rejected, even for negligible differences (Sullivan and Feinn, 2012). Therefore, Cohen's D (Cohen, 1992) was calculated as the difference between two means divided by the S.D. of the pooled data. The $\mathrm{CI}$ for Cohen's D was calculated as previously described (Coe, R., 2002. It's the effect size, stupid: what effect size is and why it is important. In, Annual Conference of the British Educational Research Association, University of Exeter, England, UK). The standard interpretation of Cohen's D is: $\leqslant 0.2$, little effect; 0.3-0.5, moderate effect; and $>0.5$, large effect (Sullivan and Feinn, 2012).

\subsubsection{Diversity and effective population size}

To evaluate genetic diversity, we used the effective allele number (Ae), calculated as $1 / \Sigma p_{i}{ }^{2}$ where $p_{i}$ is the frequency of the $i$ th allele, for each marker (Hartl and Clark, 1997). The result is reported as the mean and S.D. over all loci. Variance effective population size $(\mathrm{Ne})$ was estimated from component population allele numbers using a temporal maximum likelihood approach realised in the program MLNE (Wang and Whitlock, 2003; Wang, 2005). MLNE also performs a joint calculation of the local migration rate $(m)$ as well as a calculation of Ne based on the second moment. For estimates of $m$ at generation 0 of a given community, we used the allele frequencies from the nearby community prior to treatment in 2009 as the source population and set the generation time to 1 . For subsequent years we used the allele frequencies from the nearby community in 2012 as the source population. One generation time was estimated at 12 weeks.

\subsection{Spatial analysis}

All households and major geographic features were georeferenced using a Nomad GPS unit Model 65220-11 (Trimble Navigation Ltd., Sunnyvale, CA, USA). The spatial density of schistosome infections by household was plotted using kernel density estimation.

\section{Results}

\subsection{Study population characteristics}

In 2009 the two villages differed in population (Jenipapo 482, Volta do Rio 368), and the percentage of the population with access to a septic tank at home (Jenipapo 44\%, Volta do Rio 91\% (Barbosa et al., 2013)), but were similar for other characteristics (Table 1). There also were no significant demographic changes over the 2009-2013 period. There were nine new registrants in 2012 not born in the district and who had spent less than $25 \%$ of their lifetime in Jenipapo or Volta do Rio. Of these, two were infected with S. mansoni.

\subsection{Infection characteristics and treatment coverage}

In 2009 and 2012, 96\% of the residents of the two communities provided at least one stool sample, and $96 \%$ of these provided three stools. In 2013, when only Jenipapo was evaluated, $82 \%$ provided at least one stool with $94 \%$ of these providing three stools. In 2009, praziquantel was distributed to $88.1 \%$ of the infected individuals, and in 2012, 96.8\% were treated. Egg negative rates after a single course of praziquantel were $89.5 \%, 98.7 \%$ and $97.0 \%$ in 2009 , 2012 and 2013, respectively.

Prevalence and mean intensity of infection decreased at each follow-up period (Table 2). Between 2009 and 2012 the prevalence in Jenipapo fell from $45.8 \%$ to $23.6 \%$ and in 2013 further reduced to $16.2 \%(P<0.01$, odds ratio (OR) $1.60,95 \%$ CI 1.14-2.25, chi-square test with 1 degree of freedom (df)). In Volta do Rio prevalence went from $35.1 \%$ to $13 \%$. By contrast, the prevalence of soil-transmitted helminths increased or was unchanged despite mebendazole treatment at each period. The combined intensity of schistosome infection also showed a marked decrease from a geometric mean of 68.6 epg to 34.1 epg in $2012(P<0.001$, Student's $t$-test), but for Jenipapo the mean intensity in 2012 (34.2 epg) was not significantly different in 2013 (24.1 epg, $P=0.07$, Student's $t$-test). The total daily egg output for each community was calculated from stool weights and intensity. From 2009 to 2012, the measured total daily egg output fell 74\% and $81 \%$ in Jenipapo and Volta do Rio, respectively, and in Jenipapo the total egg count fell by $92 \%$ or $>10$ fold

Table 1

Demographic characteristics in Jenipapo (Jen) and Volta do Rio (VdR), Brazil 2009-2013.

\begin{tabular}{|c|c|c|c|c|c|c|c|c|c|}
\hline \multirow[t]{2}{*}{ Characteristic } & \multicolumn{4}{|c|}{2009 (year 1) } & \multicolumn{4}{|c|}{2012 (year 3) } & \multirow{2}{*}{$\begin{array}{l}2013 \text { (year 4) } \\
\text { Jen } 422\end{array}$} \\
\hline & Total 814 & Jen 461 & VdR 353 & $P$ & Total 810 & Jen 452 & VdR 358 & $P$ & \\
\hline Sex (\% male) & $377(46.3)$ & 221 (47.9) & $156(44.2)$ & $>0.05^{\mathrm{a}}$ & $371(45.8)$ & 212 (46.9) & $159(44.4)$ & $>0.05^{\mathrm{a}}$ & $196(46.3)$ \\
\hline Age (years) & $31.5 \pm 22.2$ & $30.6 \pm 21.7$ & $32.6 \pm 22.7$ & $>0.05^{c}$ & $32.4 \pm 21.9$ & $30.9 \pm 20.9$ & $33.9 \pm 23.0$ & $>0.05^{\mathrm{c}}$ & $33.6 \pm 20.9$ \\
\hline \multicolumn{10}{|l|}{ Birth place } \\
\hline Ubaíra (\%) & $681(83.7)$ & $391(84.8)$ & $290(82.2)$ & $>0.05^{\mathrm{a}}$ & $668(82.5)$ & $378(83.6)$ & $290(81.0)$ & $>0.05^{\mathrm{a}}$ & $335(84.2)$ \\
\hline$\%$ lifetime ${ }^{\mathrm{b}}$ & $93.5 \pm 41.4$ & $93.6 \pm 19.9$ & $93.5 \pm 58.6$ & $>0.05^{\mathrm{a}}$ & $90.9 \pm 21.7$ & $92.7 \pm 20.1$ & $9.4 \pm 22.9$ & $>0.05^{\mathrm{a}}$ & $93.7 \pm 17.8$ \\
\hline
\end{tabular}

a Chi-square test with 1 degree of freedom.

b $\%$ of lifetime spent in the county.

c Student's $t$-test. 
Table 2

Infection characteristics in Jenipapo and Volta do Rio, Brazil 2009-2013.

\begin{tabular}{|c|c|c|c|c|c|c|c|c|c|}
\hline \multirow[t]{2}{*}{ Parasite species } & \multirow[t]{2}{*}{ Intensity or prevalence } & \multicolumn{5}{|l|}{ Jenipapo } & \multicolumn{3}{|l|}{ Volta do Rio } \\
\hline & & $2009(461)$ & $2012(452)$ & $2013(423)$ & $P$ & $P$ & $2009(353)$ & $2012(358)$ & $P^{\mathrm{a}}$ \\
\hline \multirow[t]{2}{*}{ Schistosoma mansoni } & Mean intensity (epg) & 57.0 & 34.1 & 24.1 & $0.002^{\mathrm{b}}$ & $0.07^{\mathrm{c}}$ & 68.6 & 32.5 & $0.002^{\mathrm{b}}$ \\
\hline & Prevalence (\%) & 45.8 & 23.6 & 16.2 & $<0.001^{\mathrm{d}}$ & $0.002^{\mathrm{e}}$ & 35.1 & 13.0 & $<0.001^{\mathrm{d}}$ \\
\hline Trichuris trichiura & Prevalence & 18.4 & 16.2 & 11.8 & $0.36^{\mathrm{d}}$ & $0.09^{\mathrm{e}}$ & 25.0 & 22.2 & $0.49^{d}$ \\
\hline Ascaris lumbricoides & Prevalence & 7.6 & 8.0 & 6.0 & $0.92^{\mathrm{d}}$ & $0.31^{\mathrm{e}}$ & 9.9 & 15.2 & $<0.05^{\mathrm{d}}$ \\
\hline Ancylostoma duodenale & Prevalence & 11.1 & 11.8 & 9.7 & $0.55^{\mathrm{d}}$ & $0.21^{\mathrm{e}}$ & 3.1 & 18.1 & $<0.01^{\mathrm{d}}$ \\
\hline
\end{tabular}

a Geometric mean (epg) eggs per gram.

b Student's $t$-test 2009 versus 2012.

c Student's $t$-test 2012 versus 2013.

d Chi-square test with 1 degree of freedom (df) 2009 versus 2012.

e Chi-square test with 1 df 2012 versus 2013.

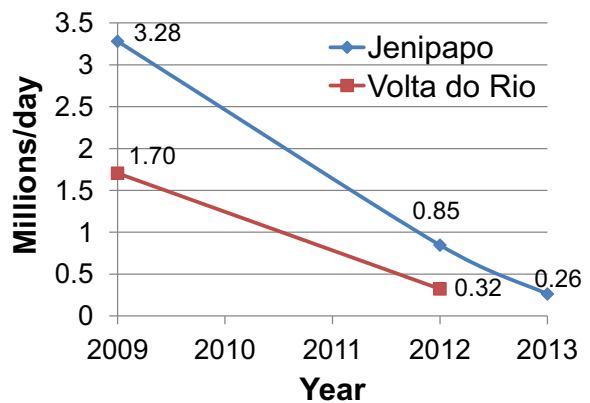

Fig. 3. Estimated total per day Schistosoma mansoni egg production (millions/day), 2009-2013. Data points represent the sum of eggs produced by all infected individuals in each community based on stool weight and mean stool egg concentration.

by 2013 (Fig. 3). The rate of decline, however, decreased after the second round of treatment in Jenipapo. The total number of eggs was always greater (up to $300 \%$ ) in those $>15$ years of age compared with those of younger age.

The incidence of schistosomiasis (Table 3) was higher in Jenipapo in 2012 (23.0) than Volta do Rio (13.8; $P<0.01$, OR 1.86, $95 \%$ CI 1.24-2.80, chi-square test with $1 \mathrm{df}$ ). Incidence declined in Jenipapo to $15.2 \%$ per year after the second round of treatment $(P<0.01$, OR $1.67,95 \%$ CI 1.17-2.40, chi-square test with $1 \mathrm{df})$. Since there were 3 and 1 years, respectively, between treatment and re-survey periods, the annual rate was actually lower after the first round. Reinfection rates were higher than incidence in previously uninfected individuals.

For both communities the 11-20 and 21-30 year age groups had the highest intensity and prevalence, and likewise showed the most reduction (Fig. 4). In 2009 the youngest person infected was 2 years old, the oldest 99 years. By 2013, the youngest infected in Jenipapo was 8 years old and the oldest 69 years.

\subsection{Longitudinal schistosome population differentiation}

DNA from samples collected each year showed similar PCR success rates $(2009=66 \% ; 2011=58.8 \% ; 2013=64.7 \%)$. The villages differed for the effect of treatment on differentiation (Table 4). There was moderate differentiation between infrapopulations for both communities at baseline. For Jenipapo this changed little after the first round of treatment (effect size 0.014 ), but was effectively higher a year after the second round $(P<0.001$, Student's $t$-test, effect size 0.332). By contrast the mean Di for Volta do Rio increased significantly after the first round of treatment $(P=0.001$, Student's $t$-test, effect size 0.330). Mean Di in samples from reinfection in the same individual showed moderate differentiation at each evaluation period (2009 versus $2012=0.055 ; 2012$ versus $2013=0.077$ ).

To test the sensitivity of the differentiation indices to allele frequency estimation error the frequency of the most common allele was reduced and in another assay increased by $10 \%$ for four markers (SMMS2, SM13-410, SMMS13 and SMU31768). Mean Di was then calculated using all of the genotypes from Jenipapo in 2009. A difference of 3,4.1, 11.4 and 3.5\% from the observed values was noted, respectively.

The Dc evaluated the differentiation between parasite component populations defined by village and year of study. Dc between villages was unchanged from 2009 to 2012 (Di $0.045 \pm 0.002$ and $0.030 \pm 0.004$, respectively, $P=0.39$, Student's $t$-test). Within each community, Dc between consecutive survey periods was small (0.008-0.013).

\subsection{Longitudinal schistosome population diversity}

The mean Ae in all years and all populations ranged from 3.5 to 3.8 and was no different between populations or between any combination of years (Table 4). Ne for Jenipapo was calculated with and without the joint estimation of the migratory fraction, $m$. The

Table 3

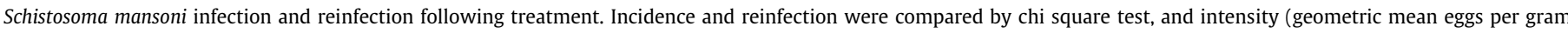
(epg) of feces) by Student's $t$-test.

\begin{tabular}{|c|c|c|c|c|c|c|}
\hline \multirow[t]{2}{*}{ Prior infection status } & & \multicolumn{2}{|c|}{2012 (year 3) } & \multirow[t]{2}{*}{$P^{\mathrm{a}}$} & \multirow{2}{*}{$\begin{array}{l}2013 \text { (year 4) } \\
\text { Jenipapo }\end{array}$} & \multirow[t]{2}{*}{$P^{\mathrm{b}}$} \\
\hline & & Jenipapo & Volta do Rio & & & \\
\hline \multirow[t]{3}{*}{ Previously uninfected } & & $(n=453)$ & $(n=357)$ & & $(n=406)$ & \\
\hline & Incidence\% $(n)$ & $23.0(107)$ & $14.0(43)$ & $<0.001$ & $15.0(61)$ & $<0.001$ \\
\hline & Intensity (epg) & 29.2 & 24.6 & 0.271 & 19.5 & 0.016 \\
\hline \multirow[t]{3}{*}{ Previously infected } & & $(n=163)$ & $(n=87)$ & & $(n=90)$ & \\
\hline & Reinfection\% ( $n)$ & $35.2(62)$ & $20.8(20)$ & 0.020 & $19.4(18)$ & 0.010 \\
\hline & Intensity & 32.6 & 44.7 & 0.398 & 23 & 0.718 \\
\hline
\end{tabular}

\footnotetext{
a 2012 Jenipapo versus Volta do Rio.

b Jenipapo 2012 versus 2013.
} 

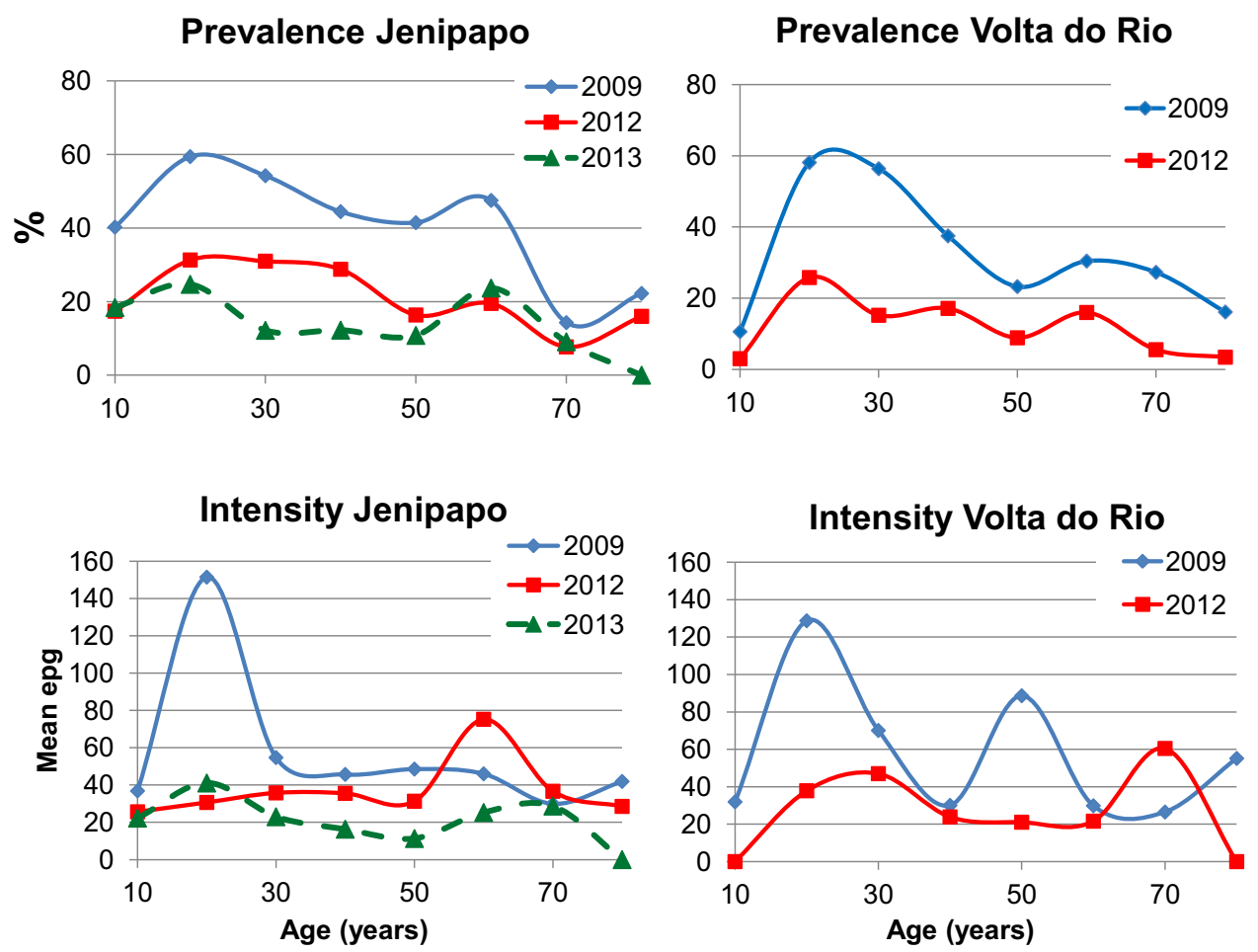

Fig. 4. Age-specific prevalence and intensity of Schistosoma mansoni infections, 2009-2013. epg, eggs per gram of feces.

Table 4

Mean Jost's D comparisons between infrapopulations (Di) and effective allele number (Ae) for each community by year.

\begin{tabular}{|c|c|c|c|c|c|c|c|c|}
\hline \multirow[t]{2}{*}{ Index } & \multicolumn{5}{|l|}{ Jenipapo } & \multicolumn{3}{|l|}{ Volta do Rio } \\
\hline & 2009 & 2012 & 2013 & $P^{\mathrm{a}}(\mathrm{ES})^{\mathrm{b}}$ & $P^{\mathrm{a}}(\mathrm{ES})^{\mathrm{c}}$ & 2009 & 2012 & $P^{\mathrm{d}}(\mathrm{ES})$ \\
\hline $\mathrm{Di} \pm \mathrm{S} . \mathrm{D}$ & $0.083 \pm 0.057$ & $0.084 \pm 0.051$ & $0.102 \pm 0.053$ & $<0.01(0.014)$ & $<0.01(0.332)$ & $0.096 \pm 0.049$ & $0.116 \pm 0.055$ & $<0.01(0.330)$ \\
\hline Ae \pm S.D. & $3.816 \pm 1.591$ & $3.553 \pm 1.564$ & $3.635 \pm 1.656$ & $0.70(0.17)$ & $0.91(0.05)$ & $3.781 \pm 1.680$ & $3.846 \pm 1.519$ & $0.92(0.040)$ \\
\hline
\end{tabular}

a ANOVA with Tukey's test for pairwise comparison for 2009, 2012, 2013.

b Effect size (ES) - Cohen's D effect size 2009-2012.

c ES - Cohen's D effect size 2012-2013.

d Student's t-test 2012-2013.

two calculations generally differed by only 7\%, and the value of $m$ was always $<0.007$ (Table 5). At baseline the variance Ne was infinite by the moments method of calculation or 33,181 by maximum likelihood. In 2012, 3 years after the first community-wide treatment, Ne fell to 1909 and then 1059 after the second treatment. The Ne in Volta do Rio was comparable with that of Jenipapo. Although the Ne was much less when estimated jointly with $m$, the CI substantially overlaps. The calculation for Volta do Rio was likewise comparable with that of Jenipapo. Ne fell to $<1000$ after the first round of treatment.

\subsection{Spatial distribution of reinfection}

In a previous study (Ponce-Terashima et al., 2014), we identified clustering of schistosome cases along the downstream portion of the Jiquiriçá River in Jenipapo, a section that corresponded to the highest concentration of human fecal contamination. In each follow-up period of this study, the distribution of infection showed decreasing prevalence along upstream portions of the river with recurrent foci of higher infection numbers downstream (Fig. 5).

Table 5

Effective population size (Ne) and migration estimates $(m)$ for Jenipapo 2009-2013.

\begin{tabular}{|c|c|c|c|c|c|}
\hline & Jenipapo & & & Volta do Rio & \\
\hline Year & 2009 & 2012 & 2013 & 2009 & 2012 \\
\hline Generation $^{\mathrm{a}}$ & 0 & 12 & 16 & 0 & 12 \\
\hline Ne (moment) & Infinite & 1369 & 512 & Infinite & 881 \\
\hline $\mathrm{Ne}(95 \% \mathrm{CI})$ & $33,181(2035-35,000)$ & $2531(2337-3280)$ & 1076 (934-1255) & $31,427(1560-35,000)$ & $1397(1170-1676)$ \\
\hline $\mathrm{Ne}(m)^{\mathrm{b}}(95 \% \mathrm{CI})$ & $31,064(1611-35,000)$ & 1467 (1137-1923) & $730(642-830)$ & $4195(1563-15,000)$ & $967(792-1203)$ \\
\hline$m(95 \% \mathrm{CI})$ & $0.001(0.001-0.174)$ & $0.002(0.001-0.003)$ & $0.004(0.003-0.007)$ & $0.001(0.001-1.000)$ & $0.007(0.005-0.010)$ \\
\hline
\end{tabular}

Ne and $m$ estimated by the program MLNE.

$\mathrm{CI}$, confidence interval.

a A generation was estimated as 12 weeks, 4.3 generations/year.

b Joint estimate of Ne and $m$. The source population at generation $=0$ was the nearby community prior to community-wide treatment. 


\section{Discussion}

The sequential analysis of parasite populations subjected to repeated treatments offers insights into the local transmission dynamics, population structure and spatial distribution of risk for schistosomiasis. Since nearly everyone with detectable infection in these communities was treated and re-examined, we were able to calculate accurate incidence and reinfection rates. Both progressively declined following treatment, and in contrast to multiple studies in Africa (Huyse et al., 2013; Lelo et al., 2014), these reductions were maintained over a 4 year period with little intervention apart from retreatment. The relative success of this program was likely due to the communities' small size, higher success rates for research over operational programs, better sanitation compared with much of Africa, education and sensitisation of the population to the problem and treatment of all identified infected individuals regardless of age. School aged children, the treatment targets in the African studies, are generally 5-14 year olds, yet most of those infected in Brazil are older than 15. Even in Africa, with the world's youngest population, the 5-14 year old age group comprises only $20-30 \%$ of the total (Rosling et al., 2005). There are, thus, more eggs produced by the older population despite higher intensity of infection in children. After community-wide treatment and retreatment, the reservoir for reinfection became relatively small, composed of immature infections not yet productive of eggs, the few individuals who refused treatment, those whose egg counts were below the level of detection and the population resident in snails. To reduce morbidity, the most heavily infected segment of the population (usually children) should be targeted, but to reduce transmission, the total number of eggs needs to be reduced. If elimination is the goal, school-based treatment may not be the best option in Brazil. Worldwide, there is a demographic shift toward aging that needs to be taken into account in long-term planning for elimination.

Despite repeated community-wide treatment, transmission was not eliminated in Jenipapo and Volta do Rio. The analysis of population structure uncovers important aspects of how the parasite population was changing and what factors permitted its persistence.

First, individuals who were positive for stool eggs 1 or 2 years after treatment are likely to have reacquired their infection rather than possess parasites insensitive to praziquantel. Comparison of the composition of populations by genetic differentiation can help distinguish reinfection from persistent infection. Infrapopulation differentiation for reinfections was moderately elevated in both 2012 and 2013, indicating that these hosts now had a different range of multilocus genotypes producing eggs. This is likely the result of death or permanent infertility in the resident worms and the acquisition of new organisms. In an earlier study, no such

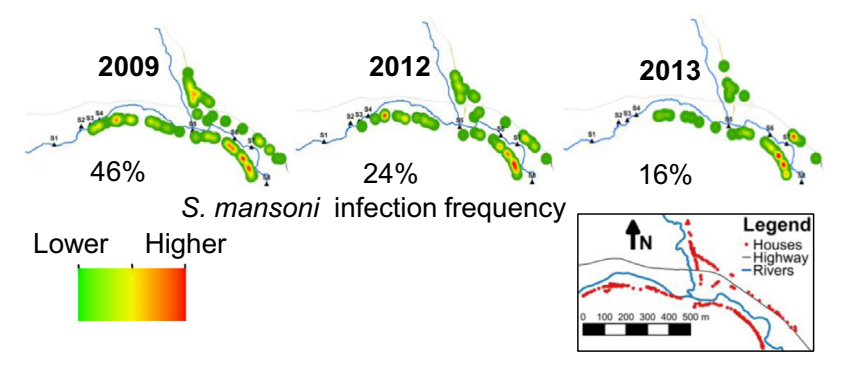

Fig. 5. Spatial distribution of Schistosoma mansoni infection/reinfection in Jenipapo, Brazil, 2009-2013. The spatial kernel density estimation of numbers of S. mansoniinfected individuals by household in each year. Detectable infections were zero at the end of 2009 and 2012. Inset shows the distribution of homes which changed little during this period. differentiation was observed in worms that persisted 6 weeks after treatment (Blanton et al., 2011). The moderate differentiation between infrapopulations upon reinfection underscores that each individual host takes an unrepresentative sample of the component population and does not merely resample the same multilocus genotypes. Small samples of parasites and small numbers of infrapopulations are likely to be problematic for interpretation.

Second, the effective population size $(\mathrm{Ne})$ responded to population decline more rapidly than differentiation or Ae. While the total production of parasite eggs fell by $>70 \%$, little effect on infrapopulation or component population differentiation was observed after the first treatment period. By contrast, Ne declined steeply after the first community-wide treatment. This is consistent with the findings of Antao et al. (2011) who showed that measures of Ne can rapidly detect small declines in the census population even after one generation. There was little change in Ne after the second round of treatment at the same time as there was slowing in the decline of total community egg burden.

Third, Ne represents the size of an ideal population needed to reproduce the genetic variability and rate of drift present in the actual population. Ne has been used as a guide to the risk for extinction (Frankham, 2005). Some have suggested that extinction in the short-term is associated with a variance $\mathrm{Ne}<50$ (Reed and Bryant, 2000; Palstra and Ruzzante, 2008), while long-term extinction (on the order of 100 years) is associated with $\mathrm{Ne}<500$ (Franklin, 1980; Franklin and Frankham, 1998) or even 5000 (Lande, 1995). Here Ne was reduced to less than 1000 in the schistosome populations of both communities. Values that would inevitably lead to extinction of a schistosome population are unknown and depend on the time frame and environmental and demographic considerations that may be specific to a locality. Beyond serving as a predictor of extinction, Ne lowered to <1000 may be associated with slow population recovery, such as we see in Brazil, and could indicate to public health officials that the interval between treatments could be increased.

Fourth, migration contributed little to continued transmission. Only two infected hosts were identified in the subsequent years who could be considered new immigrants. Consistent with the low degree of recent human and parasite migration, estimation of a parasite migratory fraction as part of the calculation of $\mathrm{Ne}$ was negligible for both communities for each year studied. In our Brazilian studies, schistosomiasis transmission was observed to be very local. The yearly plot of infection intensity in Jenipapo indicates an increasingly limited area of transmission if we assume infections occur near home as it does in other studies (Lima e Costa et al., 1991; Clennon et al., 2004; Matthys et al., 2007; Meurs et al., 2013).

A major strength of our methodology is the analysis of a large number of parasites within a large number of infected hosts. Indeed, we have captured essentially the universe of infections in the population. The ideal sample size is difficult to know, but for a heterogeneous population it should be large. This produces the most accurate and precise estimates of Ne which is strongly biased when small samples are used (Palstra and Ruzzante, 2008).

There are multiple sources of error in a field-based study such as this, including failure of participants to deliver a whole stool, production of more than one stool per day, wide day-to-day variation in egg output, heterogeneous distribution of eggs in stool and poor sensitivity of the Kato-Katz assay for low intensity infections (Engels et al., 1996; Berhe et al., 2004). Depending on which standard is used, one stool has a sensitivity of $40-60 \%$, and three stools will have a sensitivity of $90 \%$. The greatest error is for light infections, thus, on balance the underestimate of total egg numbers available to contaminate the environment should be small.

Allele frequencies estimated from pooled samples have up to a $10 \%$ difference compared with the use of discrete genotypes 
(Hanelt et al., 2009). On the other hand, this approach sometimes identifies alleles missed by analysis of discrete genotypes. For differentiation, the error should cancel for comparisons of contemporary infrapopulations and geographic comparisons. For samples taken at different times, precision may decrease as infection intensities and prevalence decline. The effect on accuracy may be unpredictable. By contrast, the error inherent in taking small discrete samples of a very large, heterogeneous population has not been estimated. Ne can be evaluated to reflect parent or progeny population size. Variation in family size may affect calculation of $\mathrm{Ne}$ for parents (Steinauer et al., 2013), but not progeny. The large sample sizes and the completeness of sampling in this study mitigate many of these potential errors, and are essential for accuracy in Ne estimates using the maximum likelihood approach (Wang, 2005).

The results of this study have direct bearing on the decision to use frequent selective or mass treatment in Brazil. Based on concerns for development of praziquantel resistance, a recommendation to only use targeted treatment after individual diagnosis or to use mass treatment only following screening of the population has been made (Geerts and Gryseels, 2000). Low Ne, and therefore high genetic drift, actually reduces the force of selection (Frankham, 2005; Palstra and Ruzzante, 2008; Hare et al., 2011), making resistance more difficult to develop. Further, the spatial fragmentation we observed in an urban setting (Blanton et al. 2015) and this rural area further lowers local Ne, reduces fitness (Burkey, 1997) and the risk of re-population or spread of a given mutation (Johansson et al., 2007). This is not to say that praziquantel resistance will not occur somewhere in the world. By some accounts varying degrees of tolerance have been observed in Egypt (Ismail et al., 1996), Senegal (Danso-Appiah and De Vlas, 2002) and possibly Kenya (Melman et al., 2009). However, in none of these cases has suspected resistance led to broad areas or contiguous foci that could be described as praziquantel-resistant, possibly due to similar landscape fragmentation. Effective treatment reduces $\mathrm{Ne}$ and increases fragmentation of parasite populations, and remains the best approach to reduce transmission apart from effective sanitation.

\section{Acknowledgements}

This work was supported by US National Institutes of Health (grant number R01 AI069195) and the Fulbright Brazil Scholar Program. Neither funding agency played a role in the study design, analysis or interpretation. We thank Farmanguinhos-FioCruz that provided praziquantel and Biomanguinhos that provided the Kato-Katz kits for this work. We also acknowledge the assistance and advice of the Municipal Secretariat of Health of Ubaíra, Brazil and the Family Health Program Clinic in Jenipapo, Brazil for the conduct of this study.

\section{Appendix A. Supplementary data}

Supplementary data associated with this article can be found, in the online version, at http://dx.doi.org/10.1016/j.ijpara.2016.01. 007.

\section{References}

Amaral, R.S., Tauil, P.L., Lima, D.D., Engels, D., 2006. An analysis of the impact of the Schistosomiasis Control Programme in Brazil. Mem. Inst. Oswaldo Cruz 101 (Suppl. 1), 79-85.

Antao, T., Perez-Figueroa, A., Luikart, G., 2011. Early detection of population declines: high power of genetic monitoring using effective population size estimators. Evol. Appl. 4, 144-154.

Barbosa, L.M., Silva, L.K., Reis, E.A., Azevedo, T.M., Costa, J.M., Blank, W.A., Reis, M.G., Blanton, R.E., 2013. Characteristics of the human host have little influence on which local Schistosoma mansoni populations are acquired. PLoS Negl. Trop. Dis. 7, e2572.

Berhe, N., Medhin, G., Erko, B., Smith, T., Gedamu, S., Bereded, D., Moore, R., Habte, E., Redda, A., Gebre-Michael, T., Gundersen, S.G., 2004. Variations in helminth faecal egg counts in Kato-Katz thick smears and their implications in assessing infection status with Schistosoma mansoni. Acta Trop. 92, 205-212.

Blank, W.A., Reis, E.A., Thiong'o, F.W., Braghiroli, J.F., Santos, J.M., Melo, P.R., Guimaraes, I.C., Silva, L.K., Carmo, T.M., Reis, M.G., Blanton, R.E., 2009. Analysis of Schistosoma mansoni population structure using total fecal egg sampling. J. Parasitol. 95, 881-889.

Blanton, R.E., Blank, W.A., Costa, J.M., Carmo, T.M., Reis, E.A., Silva, L.K., Barbosa, L.M., Test, M.R., Reis, M.G., 2011. Schistosoma mansoni population structure and persistence after praziquantel treatment in two villages of Bahia, Brazil. Int. J. Parasitol. 41, 1093-1099.

Blanton, R.E., Barbosa, L.M., Reis, E.A., Carmo, T.M., dos Santos, C.R.A., Costa, J.M., Aminu, P.T., Blank, W.A., Reis, R.B., Guimarães, I.C., Silva, L.K., Reis, M.G., 2015. The relative contribution of immigration or local increase in persistence of urban schistosomiasis in Salvador, Bahia, Brazil. PLoS Negl. Trop. Dis. 9e0003521.

Burkey, T.V., 1997. Metapopulation extinction in fragmented landscapes: using bacteria and protozoa communities as model ecosystems. Am. Nat. 150, 568591.

Carmo, E.H., Barreto, M.L., 1994. Schistosomiasis mansoni in Bahia, Brazil: historical trends and control measures. Cadernos de Saúde Pública 10, 425-439.

Clennon, J.A., King, C.H., Muchiri, E.M., Kariuki, H.C., Ouma, J.H., Mungai, P., Kitron, U., 2004. Spatial patterns of urinary schistosomiasis infection in a highly endemic area of coastal Kenya. Am. J. Trop. Med. Hyg. 70, 443-448.

Cohen, J., 1992. A power primer. Psychol. Bull. 112, 155-159.

Coura, J.R., Amaral, R.S., 2004. Epidemiological and control aspects of schistosomiasis in Brazilian endemic areas. Mem. Inst. Oswaldo Cruz 99, 13-19.

Danso-Appiah, A., De Vlas, S.J., 2002. Interpreting low praziquantel cure rates of Schistosoma mansoni infections in Senegal. Trends Parasitol. 18, 125-129.

Engels, D., Sinzinkayo, E., Gryseels, B., 1996. Day-to-day egg count fluctuation in Schistosoma mansoni infection and its operational implications. Am. J. Trop. Med. Hyg. 54, 319-324.

Ferreira, I.d.L.M., Tabosa e Silva, T.P., 2007. Mortality due to schistosomiasis in Brazil: 1980-2003. Rev. Patologia Trop. 36, 67-74.

Frankham, R., 2005. Genetics and extinction. Biol. Conserv. 126, 131-140.

Franklin, I., 1980. Evolutionary change in small populations. In: Soule, M., Wilcox, B, (Eds.), Conservation Biology: An Evolutionary Ecological Perspective. Sinauer Associates, Sunderland, MA, USA, pp. 135-140.

Franklin, I., Frankham, R., 1998. How large must populations be to retain evolutionary potential? Anim. Conserv. 1, 69-73.

Geerts, S., Gryseels, B., 2000. Drug resistance in human helminths: current situation and lessons from livestock. Clin. Microbiol. Rev. 13, 207-222.

Hanelt, B., Steinauer, M.L., Mwangi, I.N., Maina, G.M., Agola, L.E., Mkoji, G.M., Loker, E.S., 2009. A new approach to characterize populations of Schistosoma mansoni from humans: development and assessment of microsatellite analysis of pooled miracidia. Trop. Med. Int. Health 14, 322-331.

Hare, M.P., Nunney, L., Schwartz, M.K., Ruzzante, D.E., Burford, M., Waples, R.S., Ruegg, K., Palstra, F., 2011. Understanding and estimating effective population size for practical application in marine species management. Conserv. Biol. 25, 438-449.

Hartl, D.L., Clark, A., 1997. Principles of Population Genetics. Sinauer Associates, Sunderland, MA, USA

Huyse, T., Van den Broeck, F., Jombart, T., Webster, B.L., Diaw, O., Volckaert, F.A., Balloux, F., Rollinson, D., Polman, K., 2013. Regular treatments of praziquantel do not impact on the genetic make-up of Schistosoma mansoni in Northern Senegal. Infect. Genet. Evol. 18, 100-105.

Ismail, M., Metwally, A., Farghaly, A., Bruce, J., Tao, L.F., Bennett, J.L., 1996. Characterization of isolates of Schistosoma mansoni from Egyptian villagers that tolerate high doses of praziquantel. Am. J. Trop. Med. Hyg. 55, 214-218.

Johansson, M., Primmer, C.R., Merila, J., 2007. Does habitat fragmentation reduce fitness and adaptability? A case study of the common frog (Rana temporaria). Mol. Ecol. 16, 2693-2700.

Katz, N., Peixoto, S.V., 2000. Critical analysis of the estimated number of Schistosomiasis mansoni carriers in Brazil. Rev. Soc. Bras. Med. Trop. 33, $303-$ 308.

Lande, R., 1995. Mutation and conservation. Conserv. Biol. 9, 782-791.

Lelo, A.E., Mburu, D.N., Magoma, G.N., Mungai, B.N., Kihara, J.H., Mwangi, I.N., Maina, G.M., Kinuthia, J.M., Mutuku, M.W., Loker, E.S., Mkoji, G.M., Steinauer, M. L., 2014. No apparent reduction in schistosome burden or genetic diversity following four years of school-based mass drug administration in mwea, central Kenya, a heavy transmission area. PLoS Negl. Trop. Dis. 8 e3221.

Lima e Costa, M.F., Rocha, R.S., Leite, M.L. Carneiro, R.G., Colley, D. Gazzinelli, G. Katz, N., 1991. A multivariate analysis of socio-demographic factors, water contact patterns and Schistosoma mansoni infection in an endemic area in Brazil. Rev. Inst. Med. Trop. Sao Paulo 33, 58-63.

Matthys, B., Tschannen, A.B., Tian-Bi, N.T., Comoe, H., Diabate, S., Traore, M. Vounatsou, P., Raso, G., Gosoniu, L., Tanner, M., Cisse, G., N'Goran, E.K., Utzinger, J., 2007. Risk factors for Schistosoma mansoni and hookworm in urban farming communities in western Cote d'Ivoire. Trop. Med. Int. Health 12, 709-723.

Melman, S.D., Steinauer, M.L., Cunningham, C., Kubatko, L.S., Mwangi, I.N., Wynn, N. B., Mutuku, M.W., Karanja, D.M., Colley, D.G., Black, C.L., Secor, W.E., Mkoji, G.M., Loker, E.S., 2009. Reduced susceptibility to praziquantel among naturally occurring Kenyan isolates of Schistosoma mansoni. PLoS Negl. Trop. Dis. 3 e504. 
Meurs, L., Mbow, M., Boon, N., van den Broeck, F., Vereecken, K., Dieye, T.N., Abatih, E., Huyse, T., Mboup, S., Polman, K., 2013. Micro-geographical heterogeneity in Schistosoma mansoni and S. haematobium infection and morbidity in a co-endemic community in northern Senegal. PLoS Negl. Trop. Dis. 7 e2608.

Ministério da Saúde, 2010. [National Therapeutic Formulary 2010] Formulário Terapêutico Nacional 2010. Ministry of Health, Brasília, DF, Brazil.

Norton, A.J., Gower, C.M., Lamberton, P.H., Webster, B.L., Lwambo, N.J., Blair, L. Fenwick, A., Webster, J.P., 2010. Genetic consequences of mass human chemotherapy for Schistosoma mansoni: population structure pre- and postpraziquantel treatment in Tanzania. Am. J. Trop. Med. Hyg. 83, 951-957.

Palstra, F.P., Ruzzante, D.E., 2008. Genetic estimates of contemporary effective population size: what can they tell us about the importance of genetic stochasticity for wild population persistence? Mol. Ecol. 17, 3428-3447.

Ponce-Terashima, R., Koskey, A.M., Reis, M.G., McLellan, S.L., Blanton, R.E., 2014. Sources and distribution of surface water fecal contamination and prevalence of schistosomiasis in a Brazilian village. PLoS Negl. Trop. Dis. 8 e3186.
Reed, D.H., Bryant, E.H., 2000. Experimental tests of minimum viable population size. Anim. Conserv. 3, 7-14.

Rosling, O., Rosling Rönnlund, A., Rosling, H., 2005. Posting date. Gapminder World. The Gapminder Foundation, Sweden, p. 189, http://www.gapminder.org/world.

Spielman, D., Brook, B.W. Frankham, R., 2004. Most species are not driven to extinction before genetic factors impact them. Proc. Natl. Acad. Sci. U.S.A. 101, $15261-15264$.

Steinauer, M.L., Christie, M.R., Blouin, M.S., Agola, L.E., Mwangi, I.N., Maina, G.M., Mutuku, M.W., Kinuthia, J.M., Mkoji, G.M., Loker, E.S., 2013. Non-invasive sampling of schistosomes from humans requires correcting for family structure. PLoS Negl. Trop. Dis. 7 e2456.

Sullivan, G.M., Feinn, R., 2012. Using effect size-or why the P value is not enough. J. Grad. Med. Educ. 4, 279-282.

Wang, J., 2005. Estimation of effective population sizes from data on genetic markers. Philos. Trans. R Soc. Lond. B Biol. Sci. 360, 1395-1409.

Wang, J., Whitlock, M.C., 2003. Estimating effective population size and migration rates from genetic samples over space and time. Genetics 163, 429-446. 